\title{
NGHIÊN CỨU PHƯ̛̛'GG PHÁP XÁC ĐịNH MộT Số STEVIOL GLYCOSID TRONG CỎ NGỌT BẰNG PHỮ̛́NG PHÁP SẮC KÝ LỎNG HIÊUU NĂNG CAO (HPLC)
}

\author{
Lưu Thị Huyền Trang ${ }^{1,2}$, Đoàn Thị Thanh Hương², Vũ Thị Trang ${ }^{1}$ \\ Trần Cao Sơn ${ }^{1}$, Nguyễn Thị Ánh Hường ${ }^{2}$, Nguyễn Thị Minh Lọ̣i ${ }^{3}$
}

${ }^{1}$ Viện Kiểm nghiệm an toàn vệ sinh thực phẩm Quốc gia

${ }^{2}$ Truờng Đại học Khoa học Tự nhiên - Đại học Quốc gia Hà Nội

${ }^{3}$ Truoòng Đại hoc Quảng Bình

(Ngày đến tòa soạn: 8/10/2019; Ngày sủa bài sau phản biện: 15/11/2019;

Ngày chấp nhận đăng: 26/11/2019)

\section{Tóm tắt}

Nghiên cứu này phát triển phương pháp xác định đồng thời một số steviol glycosid trong mẫu cỏ ngọt bằng HPLC. Các chất phân tích được chiết ra khỏi nền mầu bằng methanol trong 60 phút và làm sạch qua cột $\mathrm{HLB}$, tách bằng sắc ký lỏng sử dụng cột $\mathrm{C} 18(250 \mathrm{~mm}$ x 4,6 mm x $5 \mathrm{~mm})$, định lượng bằng detector PDA. Thẩm định phương pháp cho kết quả đường chuẩn tuyến tính trong khoảng $1-100 \mu \mathrm{g} / \mathrm{mL}$; RSD 1,39 - 2,85\%; độ thu hồi 93 - 105\% đạt yêu cầu của AOAC. Úng dụng phương pháp phân tích 09 mẫu cỏ ngọt thu thập trên thị trường (bao gồm cỏ ngọt khô, nguyên liệu đường cỏ ngọt) cho thấy thành phần các steviol glycosid khác nhau trong các đối tượng mẫu khác nhau trong đó hàm lượng chiếm tỷ lệ lớn là steviosid và rebaudiosid $\mathrm{A}$.

Tù̀ khóa: HPLC, steviol glycosid, cỏ ngọt.

\section{1. ĐẬT VẤN ĐỀ}

Trong những năm gần đây, tiểu đường là căn bệnh nguy hiểm và có tính toàn cầu, mang đến các tác hại và hệ lụy to lớn đối với xã hội. Do đó, các nhà sản xuất đã sử dụng chất phụ gia tạo ngọt nhưng không sinh năng lượng thay thế cho đường như: saccharin, cyclamat, sucralose, acefulfam $\mathrm{K}$ và phổ biến nhất là aspartam [7]. Các hợp chất tạo ngọt tổng hợp này có ưu điểm là độ ngọt cao, phổ biến, chi phí thấp, tuy nhiên, đã có những báo cáo về mức độ không an toàn và tác dụng phụ của chất tạo ngọt tổng hợp khi được sử dụng. Trước tình hình đó, các chất tạo ngọt tự nhiên được tìm kiếm để thay thế, trong đó cây cỏ ngọt có nhiều ưu thế và đang được quan tâm chú ý nhất.

Nhóm steviol glycosid là nhóm hợp chất ngọt tự nhiên thu được từ loài cỏ ngọt, có tác dụng tạo ngọt gấp 75 - 300 lần so với đường kính. Đây là loại chất tạo ngọt không sinh năng lượng, được sử dụng trong điều trị bệnh tiểu đường, hạ đường huyết, béo phì, sâu răng, tăng huyết áp, kháng vi khuẩn, kháng nấm, kháng virus, kháng viêm. Những lợi ích to lớn đó đã thúc đẩy nhu cầu sản xuất và tiêu thụ các chất tạo ngọt tự nhiên này ngày càng tăng cao. Các hợp chất steviol glycosid được sử dụng trong các sản phẩm bánh, kẹo, nước giải khát, sản phẩm dùng cho người ăn kiêng, người hạn chế tiêu thụ chất đường. Ủy ban Chuyên gia Quốc tế về Phụ gia Thực phẩm (JECFA) đưa ra mức tiêu thụ tối đa chấp nhận hàng ngày của các hợp chất này là $4 \mathrm{mg} / \mathrm{kg}$ thể trọng/ngày.

Để kiểm soát hàm lượng steviol glycosid trong nguyên liệu và sản phẩm, cần thiết phải phát triển các phương pháp phân tích. Trên thế giới đã có một số nghiên cứu được công bố về phương pháp xác định steviol glycosid bao gồm: sắc ký lỏng khối phổ $[5,6]$, sắc ký lỏng hiệu năng cao kết hợp detector UV-Vis, PDA $[1,2,3,4,7]$. Kỹ thuật sắc ký lỏng hiệu năng cao kết hợp detector PDA có ưu điểm là phân tích nhanh, độ nhạy, độ chính xác cao và phổ biến tại các

\section{${ }^{1}$ Điên thoại:0963385124 Email: luutrang1710@gmail.com}

2 | Tạp chí KIỂM NGHIẸM VÀ AN TOÀN THỰC PHẨM (Số 4-2019) 
phòng thí nghiệm. Mục tiêu của nghiên cứu là xây dựng phương pháp xác định một số steviol glycosid trên HPLC-PDA và áp dụng quy trình để phân tích một mẫu nguyên liệu cỏ ngọt và nguyên liệu đường cỏ ngọt.

\section{HÓA CHẤT VÀ THIẾT BI}

Chất chuẩn, hóa chất: Các chất chuẩn sử dụng trong nghiên cứu: rebaudiosid $\mathrm{A}(\mathrm{Reb} \mathrm{A})$ từ Sigma Aldrich; rebaudiosid B (Reb B), rebaudiosid C (Reb C), steviosid (Stev), steviolbiosid (Stev $\mathrm{B})$, rubusosid (Rubu) và dulcosid $\mathrm{A}(\mathrm{Dul} \mathrm{A})$ từ $\mathrm{TRC}$ - Canada, các hóa chất: acetonitril, methanol, $\mathrm{NaH}_{2} \mathrm{PO}_{4}$ của Merck. Tất cả các hóa chất dùng trong nước cất hai lần đều thuộc loại tinh khiết phân tích. Các chất chuẩn được pha trong methanol.

Thiết bị: Nghiên cứu sử dụng hệ thống sắc ký lỏng hiệu năng cao của Shimadzu bao gồm: Bơm cao áp LC 20AD, bộ tiêm mẫu tự động SIL 20AHT, buồng ổn định nhiệt độ cột CTO 10ASvp, detector mảng diod PDA - M20A, cột sắc ký C18 (250 mm x 4,6 mm x $5 \mu \mathrm{m})$.

Đối tượng mẫu gồm các loại thực phẩm: thân lá bột cỏ ngọt khô, nguyên liệu đường cỏ ngọt. Các mẫu được lấy ngẫu nhiên trên địa bàn Hà Nội từ tháng 4 đến tháng 8 năm 2018.

\section{KẾT QUẢ VÀ BÀN LUẬN}

Trên cơ sở tham khảo tài liệu $[3,4,7]$ và tính chất của nhóm steviol glycosid, các yếu tố ảnh hưởng đến hiệu quả tách và xử lý mẫu được khảo sát trong nghiên cứu này gồm: điều kiện phân tích sắc ký (nồng độ và $\mathrm{pH}$ của đệm), điều kiện xử lý mẫu (dung môi chiết, thời gian chiết và làm sạch mẫu qua cột chiết pha rắn). Các điều kiện được tham khảo và giữ cố định trong các khảo sát điều kiện sắc ký gồm: cột sắc ký $\mathrm{C} 18$, tốc độ dòng $1 \mathrm{~mL} /$ phút, detector PDA bước sóng phát hiện $210 \mathrm{~nm}$, thể tích tiêm $20 \mathrm{~mL}$ pha động kênh A: đệm phosphat - Kênh B: acetonitril (68:32, v/v).

Sau khi khảo sát thu được các điều kiện tối ưu, phương pháp được đánh giá và áp dụng để phân tích một số mẫu nguyên liệu cỏ ngọt trên địa bàn Hà Nội.

\subsection{Khảo sát điều kiện sắc ký}

\subsubsection{Khảo sát nồng độ pha động}

Pha động là yếu tố quyết định đến hiệu quả tách sắc ký. Nhìn chung, pha động có thể ảnh hưởng đến: độ chọn lọc của hệ pha, thời gian lưu giữ của chất tan, hiệu lực của cột tách (đại lượng $\mathrm{N}_{\mathrm{ef}}$ ), độ phân giải của các chất, độ rộng của pic sắc ký...

Qua tham khảo tài liệu $[4,7]$ và phương pháp hiện tại của phòng thí nghiệm Viện Kiểm nghiệm an toàn vệ sinh thực phẩm quốc gia, đệm phosphat cho hiệu quả tách steviol glycosid là tốt nhất. Tiến hành khảo sát ảnh hưởng của đệm phosphat $\mathrm{NaH}_{2} \mathrm{PO}_{4}$ ở các nồng độ $5 \mathrm{mM}$, $10 \mathrm{mM}, 20 \mathrm{mM}, 50 \mathrm{mM}$ và các điều kiện khác giữ cố định như ở mục 3 . Kết quả được thể hiện ở hình $1,2,3$.

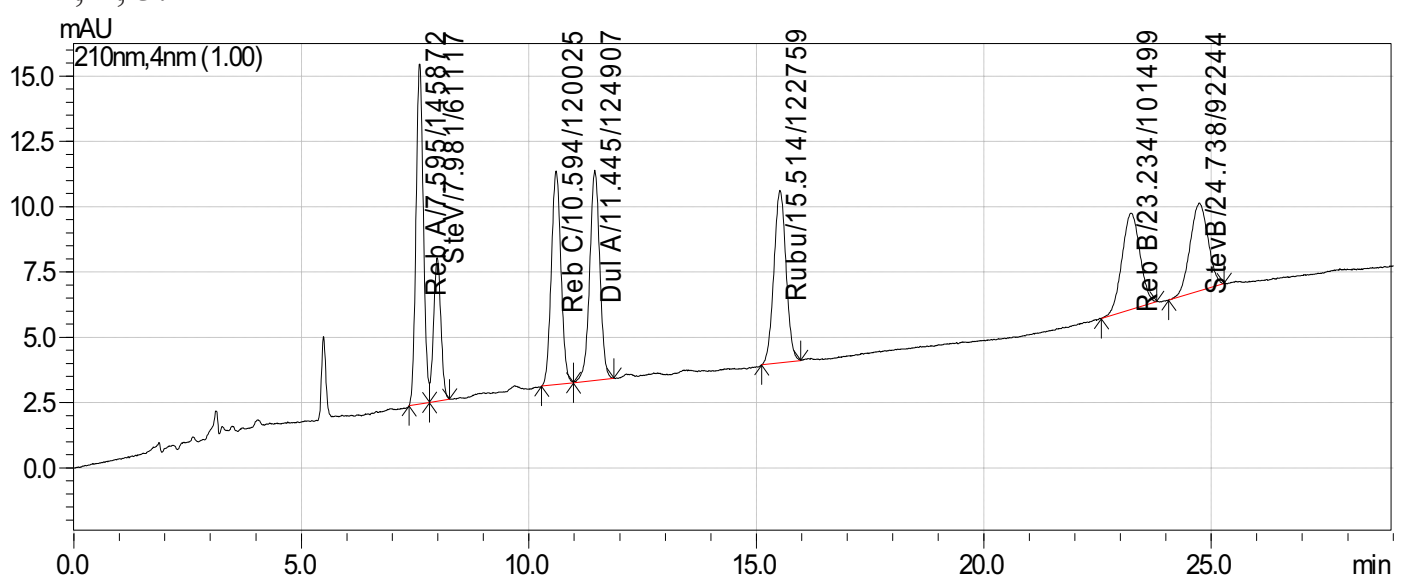

Hình 1. Sắc ký đồ 07 steviol glycosid nồng độ $25 \mu \mathrm{g} / \mathrm{mL}$ sủ dụng pha động $\mathrm{NaH}_{2} \mathrm{PO}_{4} 5 \mathrm{mM}$ 


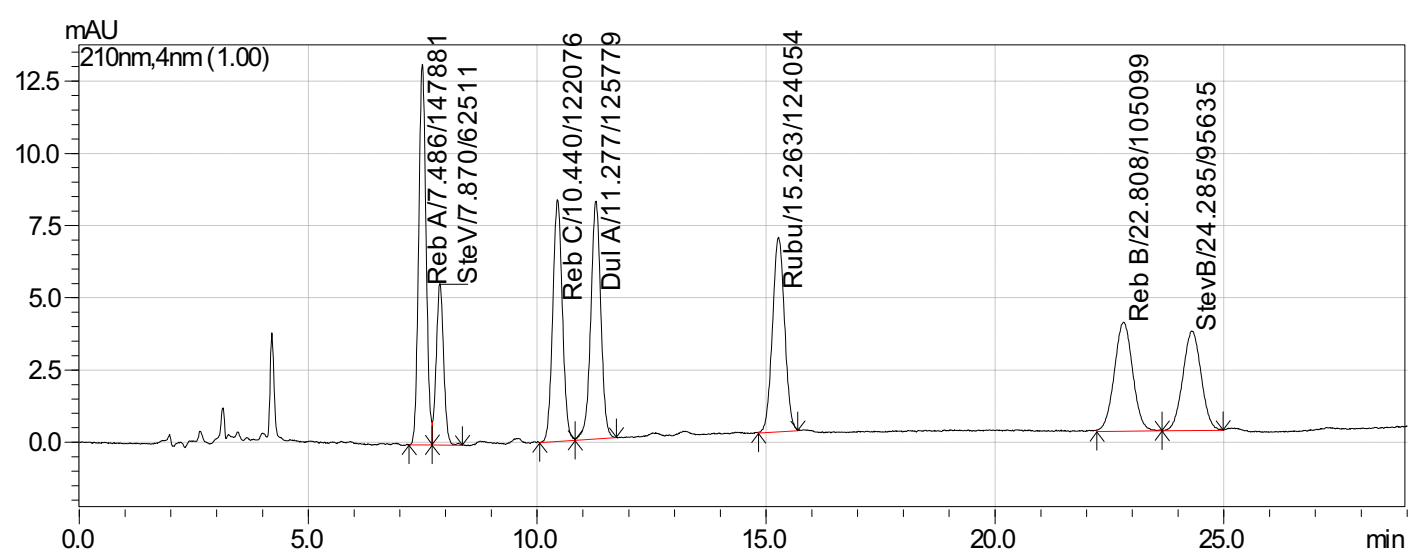

Hình 2. Sắc ký đồ 07 steviol glycosid nồng độ $25 \mu \mathrm{g} / \mathrm{mL}$ sủ dụng pha động $\mathrm{NaH}_{2} \mathrm{PO}_{4} 10 \mathrm{mM}$

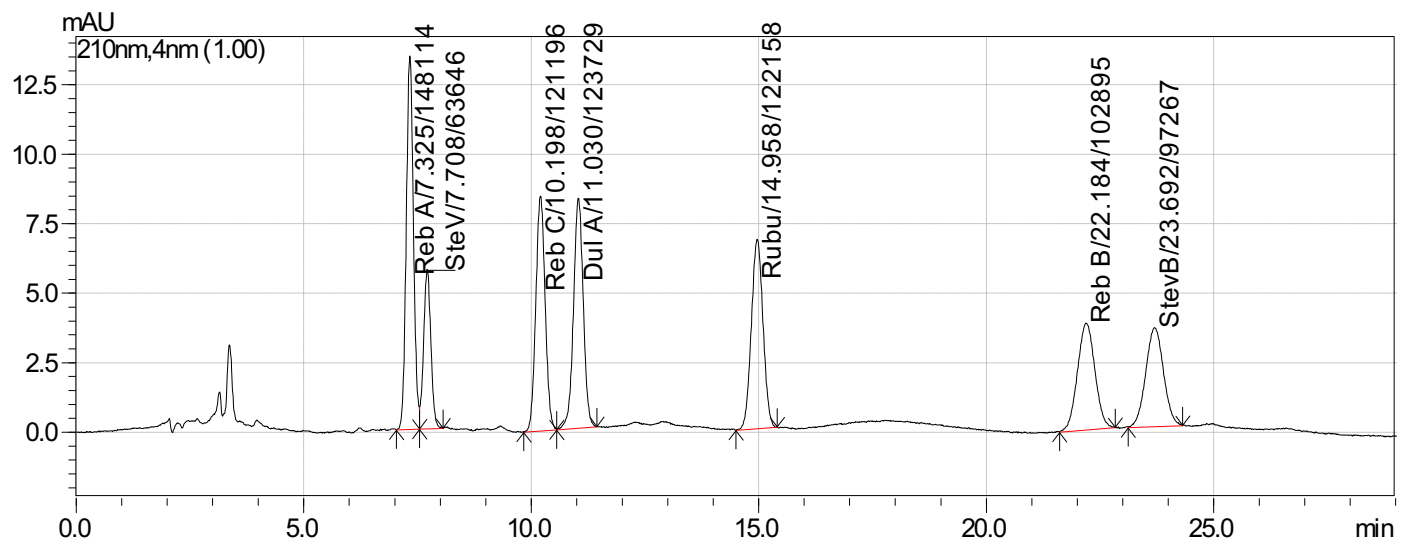

Hinh 3. Sắc ký đồ 07 steviol glycosid nồng độ $25 \mu \mathrm{g} / \mathrm{mL}$ sử dụng pha động $\mathrm{NaH}_{2} \mathrm{PO}_{4} 50 \mathrm{mM}$

Kết quả phân tích cho thấy: Với cột $\mathrm{C} 18$, khi sử dụng pha động là $\mathrm{NaH}_{2} \mathrm{PO}_{4} 5 \mathrm{mM}$ cho kết quả đường nền không tốt, ảnh hưởng bởi nền cao. Khi sử dụng pha động là $\mathrm{NaH}_{2} \mathrm{PO}_{4} 50 \mathrm{mM}$ cho pic rất nhọn, cân đối nhưng nồng độ muối cao dẫn đến ảnh hưởng đến cột, làm biến tính và giảm tuổi thọ của cột phân tích, có thể gây áp suất cao cho hệ thống bơm do hàm lượng đệm phosphat quá cao. Trong nghiên cứu này, pha động $\mathrm{NaH}_{2} \mathrm{PO}_{4} 10 \mathrm{mM}$ được lựa chọn do độ rộng chân pic nhỏ, tín hiệu chất phân tích tốt, tín hiệu nhiễu đường nền thấp, thời gian phân tích ngắn, tiết kiệm thời gian phân tích và dung môi.

\subsubsection{Khảo sát pH của pha động}

Trên cơ sở tham khảo tài liệu [7] và tính chất của nhóm steviol glycosid, pha động pH thấp thường được sử dụng để đạt được hiệu quả tách tốt. Do đó, trong nghiên cứu này, pha động $\mathrm{NaH}_{2} \mathrm{PO}_{4}$ được khảo sát với các $\mathrm{pH}$ là 2,$4 ; 2,6 ; 2,8 ; 3,0$ (điều chỉnh bằng acid orthor phosphoric $85 \%)$. Các điều kiện khác được giữ cố định như mục 3 . Kết quả được nêu trong bảng 1 .

Bảng 1. Kết quả khảo sát ảnh hưởng của pH đến thời gian lư của nhóm chất steviol glycosid

\begin{tabular}{|c|c|c|c|c|}
\hline $\boldsymbol{p H}$ & $\mathbf{2 , 4}$ & $\mathbf{2 , 6}$ & $\mathbf{2 , 8}$ & $\mathbf{3 , 0}$ \\
\hline Chất phân tich & 7,54 & 7,26 & 7,21 & 7,34 \\
\hline Stev & 7,71 & 7,91 & 7,65 & 7,72 \\
\hline Reb $\boldsymbol{A}$ & 10,53 & 10,06 & 10,12 & 10,21 \\
\hline Reb $\boldsymbol{C}$ & 11,37 & 10,90 & 10,86 & 11,04 \\
\hline Dul $\boldsymbol{A}$ & \multicolumn{3}{|r}{} \\
\hline
\end{tabular}




\begin{tabular}{|c|c|c|c|c|}
\hline Rubu & 15,35 & 14,87 & 14,96 & 14,96 \\
\hline Reb B & 23,03 & 21,98 & 22,09 & 22,19 \\
\hline Stev B & 24,49 & 23,53 & 23,50 & 23,68 \\
\hline
\end{tabular}

Dễ dàng nhận thấy, hai hợp chất chính của nhóm steviosid và rebaudiosid $\mathrm{A}$ khó tách ra khỏi nhau do có tính chất lý hóa tương tự nhau. Khi thay đổi $\mathrm{pH}$ của pha động từ $2,4-3,0$, kết quả ở $\mathrm{pH}=2,6$ cho hiệu quả tách tốt hơn cả. Do đó, $\mathrm{pH}=2,6$ được lựa chọn là điều kiện $\mathrm{pH}$ tối ưu để tách các chất steviol glycosid.

Như vậy, điều kiện tối ưu xác định steviol glucosid bằng phương pháp sắc ký lỏng hiệu năng cao bao gồm: Cột C18, detector PDA quét phổ trong khoảng 190 - $800 \mathrm{~nm}$; định lượng tại: $210 \mathrm{~nm}$; tốc độ dòng $1,0 \mathrm{~mL} /$ phút; thể tích bơm mẫu: $20 \mu \mathrm{m}$; pha động: kênh $\mathrm{A}: \mathrm{NaH}_{2} \mathrm{PO}_{4}$ $10 \mathrm{mM}, \mathrm{pH}=2,6$ - kênh B: acetonitril $(68: 32, \mathrm{v} / \mathrm{v})$.

\subsection{Khảo sát quy trình xử lý mẫu}

Các chất steviol glycosid trong phân tử có cấu trúc aglycol liên kết với gốc đường có thể hòa tan trong các dung môi phân cực. Về tính tan, một số hợp chất lại tan tốt trong các dung môi như ethanol, methanol hơn tan trong nước. Do đó, các dung môi được lựa chọn để khảo sát chiết mẫu trong nghiên cứu gồm ethanol, nước, hỗn hợp nước - methanol $(5: 5, \mathrm{v} / \mathrm{v})$, acetonitril $(\mathrm{ACN})$ và methanol. Khảo sát cho thấy kết quả tốt nhất khi sử dụng methanol đối với tất cả các steviol glycosid. Một số hợp chất như Stev, Reb $B$ và Stev $B$ có hiệu suất thấp khi tỷ lệ nước cao, tăng khi tỷ lệ methanol tăng do khả năng hòa tan trong methanol tốt hơn. Kết quả thể hiện trong bảng 2 .

Bảng 2. Kết quả khảo sát ảnh huởng của dung môi chiết

đến hàm lượng của nhóm chất steviol glycosid

\begin{tabular}{|c|c|c|c|c|c|c|c|}
\hline $\begin{array}{c}\text { Dung môi } \\
\text { chiết }\end{array}$ & $\begin{array}{c}\text { RebA } \\
(\mathbf{m g} / \mathbf{g})\end{array}$ & $\begin{array}{c}\text { Stev } \\
(\mathbf{m g} / \mathbf{g})\end{array}$ & $\begin{array}{c}\text { RebC } \\
(\mathbf{m g} / \mathbf{g})\end{array}$ & $\begin{array}{c}\text { DulA } \\
(\mathbf{m g} / \mathbf{g})\end{array}$ & $\begin{array}{c}\text { Rubu } \\
(\mathbf{m g} / \mathbf{g})\end{array}$ & $\begin{array}{c}\text { RebB } \\
(\mathbf{m g} / \mathbf{g})\end{array}$ & $\begin{array}{c}\text { StevB } \\
(\mathbf{m g} / \mathbf{g})\end{array}$ \\
\hline Methanol & 12,077 & 46,678 & 3,538 & 0,803 & 0,702 & 0,694 & 0,423 \\
\hline Methanol 50\% & 11,790 & 44,601 & 3,534 & 0,760 & 0,643 & 0,590 & 0,400 \\
\hline ACN & 0,309 & 0,287 & 0,040 & 0,266 & 0.607 & 0,040 & 0,050 \\
\hline $\boldsymbol{H}_{2} \boldsymbol{O}$ & 12,242 & 42,057 & 3,250 & 0,685 & 0,432 & 0,546 & 0,577 \\
\hline Ethanol & 4,852 & 2,375 & 1,499 & 0,125 & 0,837 & 0,265 & 0,465 \\
\hline
\end{tabular}

Sau khi tối ưu dung môi chiết, thời gian chiết cũng được khảo sát ở 15, 30, 60, 90 phút. Kết quả cho thấy, hàm lượng chất thu được tăng khi thời gian chiết tăng. Từ sau 60 phút, không có sự khác nhau nhiều về hàm lượng steviol glycosid thu được. Do đó, thời gian chiết 60 phút được lựa chọn cho các khảo sát tiếp theo.

Để làm sạch và làm giàu mẫu phân tích, kỹ thuật chiết pha rắn được lựa chọn. Kết quả khảo sát trên cột SPE C18 - Supelco $(500 \mathrm{mg}, 3 \mathrm{~mL})$, và cột Oasis HLB $(60 \mathrm{mg}, 3 \mathrm{~mL})$ cho thấy hiệu năng của cột Oasis HLB cao hơn, hiệu suất thu hồi đạt 92,6 - 100,0\% so với cột C18 - Sulpeco chỉ từ 50,0 - 95,1\%. Do đó, cột được lựa chọn là Oasis HLB để làm sạch mẫu trong nghiên cứu này.

Quy trình xử lý mẫu sau khi đã được tối ưu: Cân mẫu đã đồng nhất từ $0,1-1 \mathrm{~g}$ vào ống ly tâm $50 \mathrm{~mL}$. Thêm $30 \mathrm{~mL}$ methanol. Lắc vortex 1 phút. Rung siêu âm ở trong 60 phút. Ly tâm 5000 vòng/phút. Chuyển dịch chiết vào bình định mức $50 \mathrm{~mL}$. Chiết lặp lần hai với $15 \mathrm{~mL}$ methanol, 
gộp dịch chiết và định mức đến vạch, lọc qua giấy lọc băng xanh. Lấy $1 \mathrm{~mL}$ dịch lọc, pha loãng với $2 \mathrm{~mL}$ nước cất và nạp vào cột $\mathrm{SPE}$ Oasis $\mathrm{HLB}(60 \mathrm{mg}, 3 \mathrm{~mL})$. Cột được hoạt hóa trước với $3 \mathrm{~mL}$ methanol, $3 \mathrm{~mL} \mathrm{H}_{2} \mathrm{O}$. Nạp mẫu với tốc độ $2 \mathrm{~mL} /$ phút, rửa tạp với $3 \mathrm{~mL} \mathrm{H}_{2} \mathrm{O}, 3 \mathrm{~mL} \mathrm{MeOH}$ : $\mathrm{H}_{2} \mathrm{O}$ (4:6). Rửa giải với $3 \mathrm{~mL} \mathrm{MeOH}: \mathrm{H}_{2} \mathrm{O}$ (7:3). Phân tích trên hệ HPLC với detector PDA.

\subsection{Thẩm định phương pháp}

Độ đặc hiệu của phương pháp được đánh giá thông qua việc phân tích mẫu trắng, mẫu chuẩn và mẫu thêm chuẩn. Kết quả chỉ ra mẫu trắng không cho tín hiệu chất phân tích, mẫu chuẩn và mẫu thêm chuẩn cho tín hiệu chất phân tích tại cùng thời gian lưu cho thấy phương pháp có độ đặc hiệu tốt. Kết quả được thể hiện ở hình 5 và hình 6.

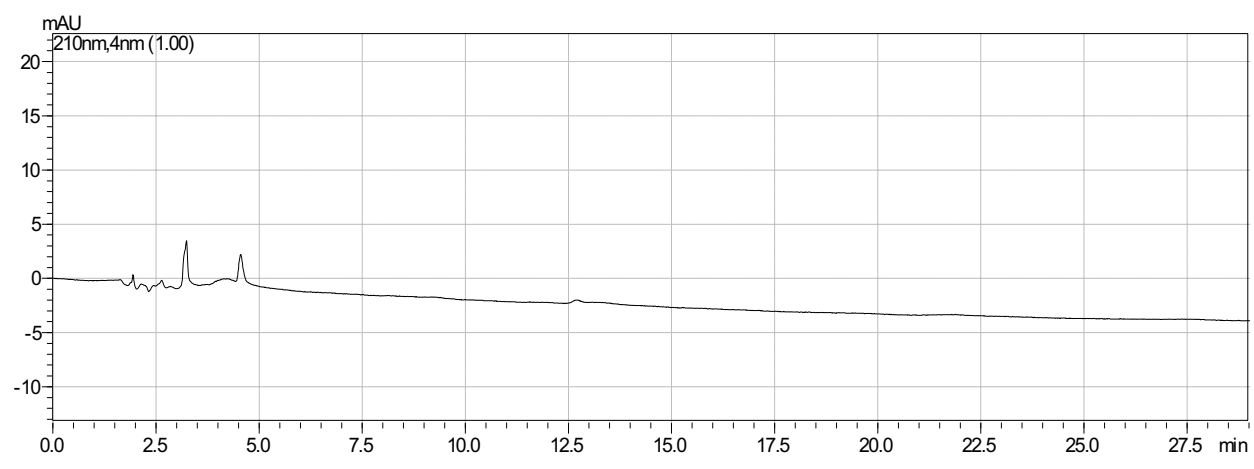

Hình 5. Sắc ký đồ mẫu trắng

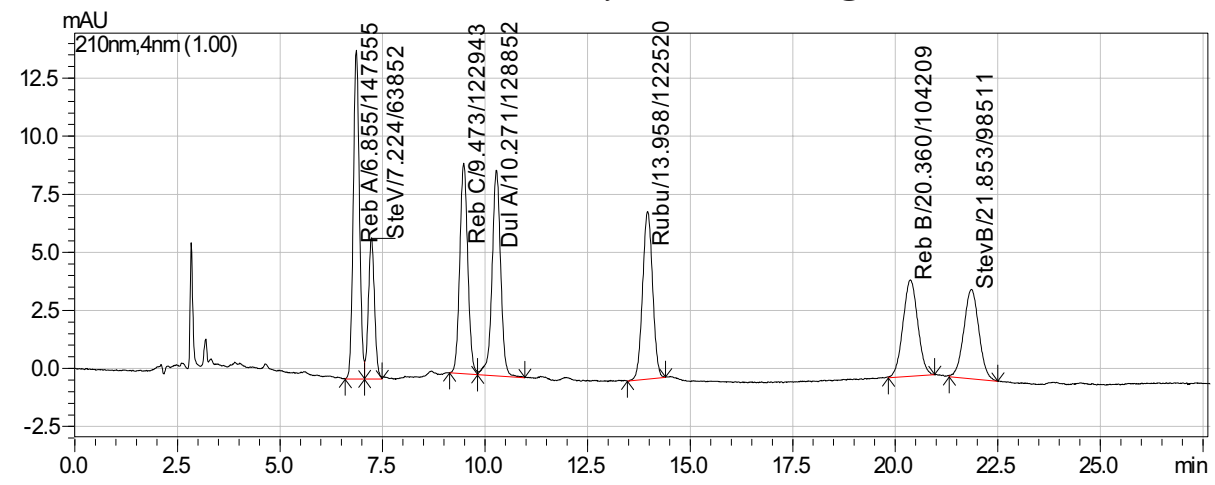

Hình 6. Sắc ký đồ mẫu thêm chuẩn 07 steviol glycosid

Trên cơ sở điều kiện tối ưu thu được, đường chuẩn phân tích 07 hợp chất steviol glycosid được xây dựng trong khoảng nồng độ $1-100 \mu \mathrm{g} / \mathrm{mL}$. Kết quả phương trình đường chuẩn, hệ số tương quan, giới hạn phát hiện (MDL) và giới hạn định lượng (MQL), độ lặp lại $(\mathrm{RSD})$ và độ thu hồi $(\mathrm{R})$ của các chất phân tích được trình bày trong Bảng 3 .

Bảng 3. Kết quả đánh giá phuoong pháp phân tích

\begin{tabular}{|c|l|c|c|c|c|c|}
\hline Tên chất & $\begin{array}{c}\text { Phương trình } \\
\text { dừ̀ng chuẩn }\end{array}$ & $\begin{array}{c}\text { Hệ số tuơng } \\
\text { quan } \boldsymbol{R}^{2}\end{array}$ & $\begin{array}{c}\text { MDL } \\
(\mathbf{m g} / \mathbf{k g})\end{array}$ & $\begin{array}{c}\text { MQL } \\
(\mathbf{m g} / \mathbf{k g})\end{array}$ & $\boldsymbol{R S D}(\%)$ & $\boldsymbol{R}(\%)$ \\
\hline Stev & $\mathrm{y}=5983,8 \mathrm{x}-2049,7$ & 1,0000 & 12,5 & 41,2 & $1,39-1,74$ & $97-103$ \\
\hline Reb $\boldsymbol{A}$ & $\mathrm{y}=2580,2 \mathrm{x}-1195,2$ & 0,9999 & 25,0 & 82,5 & $2,48-2,66$ & $97-103$ \\
\hline Reb $\boldsymbol{C}$ & $\mathrm{y}=4930 \mathrm{x}-1683,8$ & 1,0000 & 12,5 & 41,2 & $1,73-1,77$ & $96-99$ \\
\hline Dul $\boldsymbol{A}$ & $\mathrm{y}=5128,7 \mathrm{x}-1085,5$ & 0,9998 & 12,5 & 41,2 & $2,25-2,85$ & $95-104$ \\
\hline Rubu & $\mathrm{y}=5049,4 \mathrm{x}-169,67$ & 1,0000 & 12,5 & 41,2 & $2,75-3,32$ & $96-105$ \\
\hline
\end{tabular}

6 | Tạp chí KIỂM NGHIỆM VÀ AN TOÀN THỤC PHẨM (Số 4-2019) 
NGHIÊN CỨU KHOA HỌC

\begin{tabular}{|c|c|c|c|c|c|c|}
\hline Tên chất & $\begin{array}{c}\text { Phương trình } \\
\text { đường chuẩn }\end{array}$ & $\begin{array}{c}\text { Hệ số tương } \\
\text { quan } \boldsymbol{R}^{2}\end{array}$ & $\begin{array}{c}\mathbf{M D L} \\
(\mathbf{m g} / \mathbf{k g})\end{array}$ & $\begin{array}{c}\text { MQL } \\
(\mathbf{m g} / \mathbf{k g})\end{array}$ & $\boldsymbol{R S D}$ (\%) & $\boldsymbol{R}$ (\%) \\
\hline Reb B & $\mathrm{y}=4203,3 \mathrm{x}-1229,8$ & 1,0000 & 12,5 & 41,2 & $2,37-3,10$ & $95-103$ \\
\hline Stev B & $\mathrm{y}=3888,4 \mathrm{x}+315,66$ & 0,9999 & 12,5 & 41,2 & $1,14-2,37$ & $93-103$ \\
\hline
\end{tabular}

Hệ số tương quan tuyến tính $\mathrm{R}^{2}>0,99$ đối với tất cả các chất phân tích được lựa chọn, độ lặp lại và độ thu hồi đều đạt yêu cầu theo AOAC. Phương pháp hoàn toàn có thể áp dụng để phân tích hàm lượng steviol glycosid trong mẫu thực tế.

\subsection{Phân tích hàm lượng các steviol glycosid trong một số mẫu thực tế}

Tiến hành xác định hàm lượng các chất steviol glycosid trên 09 mẫu nguyên liệu cỏ ngọt. Kết quả phân tích được thể hiện trong bảng 4.

Bảng 4. Kết quả phân tích mẫu thực tế

\begin{tabular}{|c|c|c|c|c|c|c|c|c|}
\hline STT & Tên mẫu & $\begin{array}{c}\text { Stev } \\
(\mathbf{m g} / \mathbf{g})\end{array}$ & $\begin{array}{c}\text { Reb A } \\
(\mathbf{m g} / \mathbf{g})\end{array}$ & $\begin{array}{c}\text { Reb C } \\
(\mathbf{m g} / \mathbf{g})\end{array}$ & $\begin{array}{c}\text { Dul A } \\
(\mathbf{m g} / \mathbf{g})\end{array}$ & $\begin{array}{c}\text { Rubu } \\
(\mathbf{m g} / \mathbf{g})\end{array}$ & $\begin{array}{c}\text { Reb B } \\
(\mathbf{m g} / \mathbf{g})\end{array}$ & $\begin{array}{c}\text { Stev B } \\
(\mathbf{m g} / \mathbf{g})\end{array}$ \\
\hline 1 & $\begin{array}{c}\text { Nguyên liệu } \\
\text { Stevia 1 }\end{array}$ & 361 & 405 & 133 & 1,64 & 1,55 & - & 2,23 \\
\hline 2 & $\begin{array}{c}\text { Nguyên liệu } \\
\text { Stevia 2 }\end{array}$ & 732 & 232 & 30,4 & 2,84 & 3,93 & 4,82 & 1,25 \\
\hline 3 & Lá cỏ ngọt 1 & 31,9 & 11,5 & 3,32 & 0,04 & - & - & - \\
\hline 4 & Lá cỏ ngọt 2 & 54,9 & 8,52 & 2,14 & 0,15 & - & - & - \\
\hline 5 & Lá cỏ ngọt 3 & 35,5 & 9,25 & 1,28 & 0,05 & - & - & - \\
\hline 6 & Lá cỏ ngọt 4 & 25,5 & 6,25 & 0,25 & - & - & 0,04 & - \\
\hline 7 & Bột cỏ ngọt 1 & 61,5 & 3,85 & 3,56 & 1,85 & - & - & - \\
\hline 8 & Bột cỏ ngọt 2 & 54,1 & 3,35 & 1,89 & 0,75 & 0,04 & - & - \\
\hline 9 & Cành cỏ ngọt & 1,21 & 0,18 & 0,28 & - & - & - & - \\
\hline
\end{tabular}

(-): dưới nguõng phát hiện của phuơng pháp (giá trị MDL của mỗi chất theo bảng 3)

Hàm lượng các steviol glycosid rất khác nhau trong các mẫu khác nhau, có thể do điều kiện canh tác và mùa vụ thu hoạch. Hàm lượng tổng các steviol glycosid là $32,0-65,7 \mathrm{mg} / \mathrm{g}$ trong mẫu lá cỏ ngọt, $60,1-70,8 \mathrm{mg} / \mathrm{g}$ trong các mẫu bột cỏ ngọt, với các mẫu nguyên liệu stevia hàm lượng đạt ngưỡng gần $100 \%$. Hàm lượng cao nhất tập trung vào hợp chất steviosid và rebaudiosid $\mathrm{A}$, kết quả này phù hợp với các nghiên cứu trước đó về thành phần của nhóm steviol glycosid trong cây cỏ ngọt $[1,2,3]$.

\section{KẾT LUẬN}

Nghiên cứu đã thành công trong việc xác định đồng thời 07 steviol glycosid bằng phương pháp sắc ký lỏng hiệu năng cao và áp dụng quy trình phân tích tối ưu để xác định hàm lượng steviol glycosid trong một số mẫu nguyên liệu cỏ ngọt và nguyên liệu đường cỏ ngọt. Quy trình phân tích nhanh, đơn giản, phương pháp đảm bảo độ nhạy và độ chính xác để xác định hàm lượng 07 steviol glycosid trong mẫu với hàm lượng ở các dải nồng độ khác nhau. 


\title{
TÀI LIỆU THAM KHẢO
}

1. Tôn Nữ Liên Hương, Võ Hoàng Duy, Dương Mộng Hòa, Đỗ Duy Phúc và Nguyễn Duy Thanh, (2015), "Chiết xuất Stevioside từ cây cỏ ngọt", Tạp chí Khoa học, Trương Đại học Cần Thơ, Phần A: Khoa học Tự nhiên, Công nghệ và Môi truờng: 36 (2015), 73 - 76

2. Nguyễn Kim Cẩn, Lê Nguyệt Nga (2001), "Định lượng steviosid trong lá cỏ ngọt", Công trình Nghiên cứu Khoa học 1987-2000, Viện Duợc liệu, Nhà Xuất bản Khoa học và Kỹ thuật: 125 - 128.

3. Annie Shirwaikar, Vinit Parmar, Jay Bhagat and Saleemulla Khan ( 2011), "Identification and estimation of stevioside in the commercial samples of stevia leaf and powder by HPTLC and HPLC", International Journal of Pharmacy \& Life Science (IJPLS), 2, 9, $1050-1058$.

4. Prepared at the 73rd JECFA (2010) and published in FAO JECFA Monographs, Steviol glycoside, INS no. 960.

5. Molina-Calle, M., Sánchez de Medina, V., Delgado de la Torre, M. P., Priego - Capote, F., \& Luque de Castro, M. D. (2016), "Development and application of a quantitative method based on LC - QqQ MS/MS for determination of steviol glycosides in Stevia leaves", Talanta, 154 (C), 263 - 269.

6. Václav Pavlíc`ek, Petr Tuma, (2017), "The use of capillary electrophoresis with contactless conductivity detection for sensitive determination of stevioside and rebaudioside A in foods and beverages", Food Chemistry, 219, 193 - 198.

7. Venkata Sai Prakash Chaturvedula, Julian Zamora, (2014), "Reversed-Phase HPLC analysis of steviol glycoside isolated from stevia rebaudiana bertoni", Food and Nutrition Sciences, 5, 18 (9), 1703 - 1719.

\section{Summary}

SIMULTANEOUS DETERMINATION OF STEVIOL GLYCOSIDES IN STEVIA BY HIGH PERFORMANCE LIQUID CHROMATOGRAPHY

\author{
Luu Thi Huyen Trang ${ }^{1,2}$, Doan Thi Thanh Huong ${ }^{2}$, Vu Thi Trang ${ }^{1}$ \\ Tran Cao Son ${ }^{1}$, Nguyen Thi Anh Huong ${ }^{2}$, Nguyen Thi Minh Loi ${ }^{3}$ \\ ${ }^{1}$ National Institute for Food Control \\ ${ }^{2}$ VNU University of Science - Vietnam National University, Hanoi \\ ${ }^{3}$ Quang Binh University
}

A method for determination of steviol glucosides in stevia using high performance liquid chromatography was developed and validated. The compounds were extracted from the matrices with methanol for 60 minutes, cleaned by Oasis HLB column and then determined by HPLC using C18 column ( $250 \mathrm{~mm} \times 4.6 \mathrm{~mm} \times 5 \mu \mathrm{m})$ and PDA detector. The calibration curves were linear in range of 1 to $100 \mu \mathrm{g} / \mathrm{mL}$; the RSD was of $1.39-2.85 \%$; and the recovery was of $93-105 \%$. The method was applied to analyze 09 stevia samples collected from markets in Hanoi (including dry stevia rebaudiana, stevia powder). The results showed that composition of steviol glycosides differs from sample to sample. Besides, stevioside and rebaudioside A are the most abundant steviol glycosides in the samples.

Keywords: HPLC, steviol glycosides, stevia. 